\title{
Reactions of Uracil Derivatives with Phenylhydrazine
}

\author{
KazUyoshi IKeda and Yoshinisa Mizuno \\ Faculty of Pharmacentical Sciences, Hokkaido University ${ }^{1)}$
}

(Received September 14, 1970)

\begin{abstract}
Structures of Levene's 5-phenylhydrazinouracil derivatives (VIII) and 5,6-diphenylhydrazinouridine (III) formed by reactions of 5 -hydroxyuracil derivatives and brominated uridine with phenylhydrazine, were revised to 5-oxo-5,6-dihydrouracil phenylhydrazone derivatives (XI) and 5-oxo-6-phenylhydrazino-5,6-dihydrouridine phenylhydrazone (IIa), respectively, by means of physical analyses. These resolutions were substantiated by the separation of optical active isomers of compound IIa and by proving the existence of syn- and anti-isomers with the compounds of XI type, except 5-oxo-5,6-dihydrouridine phenylhydrazone (VII).
\end{abstract}

Uric acid 3-ribofuranoside has been isolated from calf blood and is one of the interestingclass of compounds in the nucleoside field. ${ }^{2)} \quad$ The chemical syntheses of uric acid 3-ribofuranoside have been reported by some investigators. ${ }^{3)}$ However, no rigorous proof has been made on the configuration of the glycosyl linkage. It was thought by us that if uric acid 3-ribofuranoside could be derived from uridine whose configuration has been definitely established, the glycosyl configuration of the calf blood-uric acid riboside might be easily deduced by comparison of the natural and synthetic samples.

In this attempted synthesis of the uric acid riboside, Levene's diphenylhydrazinouridine ${ }^{4}$ appeared a most attractive intermediate, because it has been readily obtained from uridine and besides it might be also readily converted into the target nucleoside by way of 5,6 -diaminouridine.

During the course of the synthetic work on the uric acid 3-riboside, it was felt mandatory to re-examine the structure of "Levene's phenylhydrazinouracil (VIII)" as well as "Levene's diphenylhydrazinouridine (III)," mainly because of peculiar behaviors on reduction and their spectral properties incompatible with the assigned structures.

The present paper will mainly deal with the correction of the structure of "Levene's compounds; III and VIII," which are really 5-oxo-6-phenylhydrazino-5,6-dihydrouridine phenylhydrazone (IIa) and 5-oxo-5,6-dihydrouracil phenylhydrazone (XI-A), respectively.

"5-Phenylhydrazinouracil (VIII)" was prepared by treatment of 5-hydroxyuracil with phenylhydrazine in acetate buffer $(\mathrm{pH} 4)$ according to a reported method. ${ }^{4)}$ The compound possessed the chemical formula compatible with $\mathrm{C}_{10} \mathrm{H}_{10} \mathrm{O}_{2} \mathrm{~N}_{4}$ as expected. However, it turned out that the nuclear magnetic resonance (NMR) spectral properties were incompatible with the phenylhydrazinouracil structure. Thus, the phenylhydrazino structure (VIII) has four protons exchangable with deuterium in $\mathrm{D}_{2} \mathrm{O}$ solution; two on $\mathrm{N}_{1}$ and $\mathrm{N}_{3}$, two in hydrazino system. However, in this solution, signals due to only three protons $(\delta 7.80(1 \mathrm{H}), 10.13$ $(1 \mathrm{H}), 10.32(1 \mathrm{H}))$ did indeed disappear, but signal at $\delta 4.2(2 \mathrm{H}) \mathrm{ppm}$ failed to disappear. Ultraviolet absorption (UV) spectra of this substance (mp $252^{\circ}$ ) showed maximum at 340 $\mathrm{m} \mu$ and the crystal (mp $243^{\circ}$ ) which was obtained by heating this substance $\left(\mathrm{mp} 252^{\circ}\right.$ ) in

1) Location: Kita 12, Nishi 6, Sapporo.

2) H.S.Forrest, D. Hatfield and R.R. Rinehart, J. Chem. Soc., 1961, 963.

3) a) R. Lahrmann, J.M. Lagowski and H.S. Forrest, J. Chem. Soc., 1964, 451; b) L. Birkofer, A. Ritter and H.P. Kuhlthan, Angew. Chem., 75, 209 (1963); idem, Chem. Ber., 97, 934 (1964).

4) P.A. Levene, J. Biol. Chem., 63, 653 (1925). 


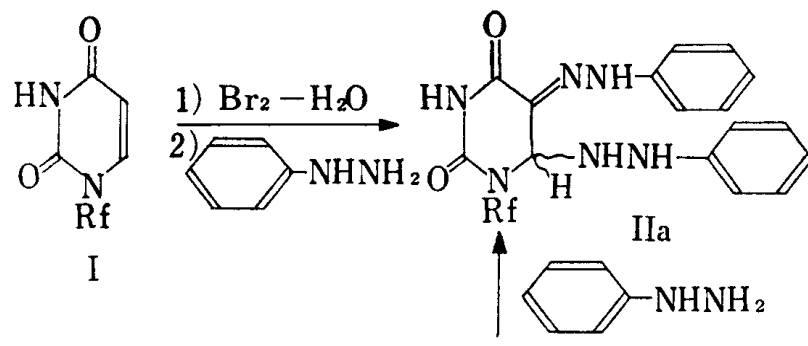

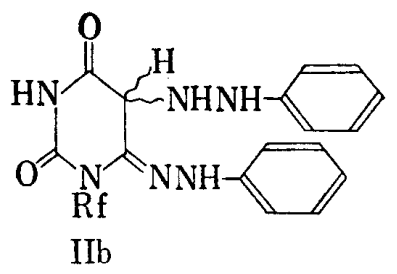

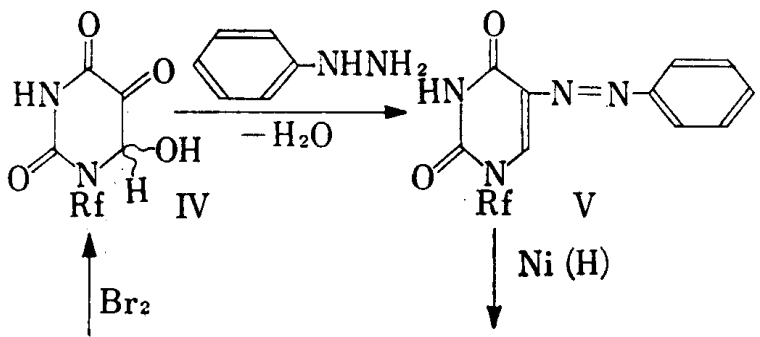<smiles></smiles>

III<smiles>[R11]CC(=NNc1ccccc1)C(=O)NC(=O)Nc1ccc(O)c(C)c1</smiles><smiles>O=c1[nH]cc(NNc2ccccc2)c(=O)[nH]1</smiles>

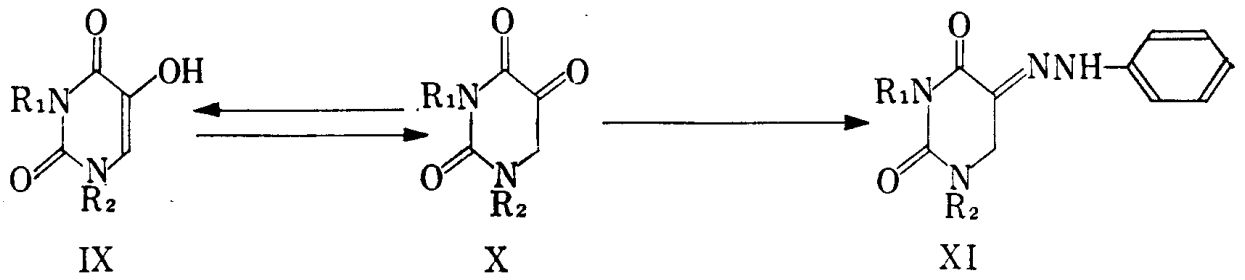

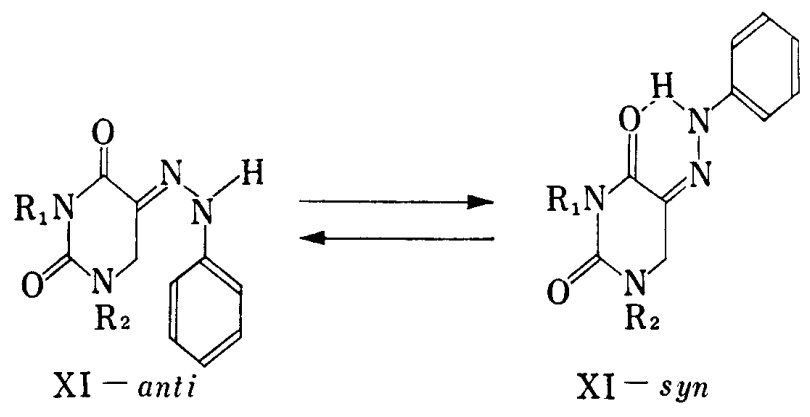

$\mathrm{Rf}=-\beta-\mathrm{D}-$ ribofuranosyl

series $A: R_{1}, R_{2}=H$

series $B: R_{1}=H, \quad R_{2}=C_{3}$

series $C: R_{1}, R_{2}=C_{3}$

Chart 1

methyl cellosolve, followed by rapid cooling showed a different absorption maximum at $360 \mathrm{~m} \mu$. These spectral change must be a reflection of the structural change on heating.

Absorption maximum $(360 \mathrm{~m} \mu)$ of the crystal in the dimethyl sulfoxide (DMSO) solution shifted gradually almost to the original maximum $(342 \mathrm{~m} \mu)$ on standing at room temperature. In the NMR spectra, the signals of " 342 m $\mu$ substance" appeared at $\delta 10.13$ and 10.32 , whose signal areas were equivalent to 0.75 proton, and at $\delta 10.40$ and 12.53 (both signal areas were equivalent to 0.25 proton). This data suggested that " $342 \mathrm{~m} \mu$ substance" consisted of two. 
different species of substances of the same composition mixed in the ratio $3: 1$. The UV spectral behaviors of "Levene's VIII" mentioned above, reminded us of Spencer's report ${ }^{5)}$ 'dealing with the syn-anti isomerism of methyl pyruvate phenylhydrazone. Taking Spencer's observations into consideration, it was concluded that the crystal obtained by the reaction of 5-hydroxyuracil with phenylhydrazine, should be assigned anti-form of 5-oxo-5,6-dihydrouracil phenylhydrazone (XIA-anti). The anti-form was converted to syn-form (XIA-syn) by heating in methyl cellosolve and the syn-form was gradually reconverted to the anti-form on standing in DMSO. The similar phenomena were observed in N-methyl derivatives (XIB, XIC). However, 5-oxo-5,6-dihydrouridine phenylhydrazone (VII) was isolated only in antiform. The compound VII could be also prepared by the catalytic reduction of 5-phenylazouridine (V) discussed later. The NMR data of these phenylhydrazone derivatives were shown in Table I. The signals at about $12.50 \mathrm{ppm}$ may come from the proton of syn-form hydrazone system which might be hydrogen bonded with carbonyl at position 4 . The formation of these phenylhydrazone derivatives suggests that 5-hydroxyuracil derivatives exist partly in the keto form $(\mathrm{X})$, which reacted with phenylhydrazine. The presence of the 5-keto tautomers at $\mathrm{pH} 4$ is indicated by the following data. When 5-hydroxyuridine was heated with -deuterated acetic acid-sodium acetate at $\mathrm{pD} 4$, the proton at position 6 was replaced with deuterium, which reflected in disappearance of the signal due to this proton. From the $\mathrm{D}_{2} \mathrm{O}$ solution, 6-deutero-5-hydroxyuridine was obtained as crystals. Similar phenomena have been reported with alkaline $\mathrm{D}_{2} \mathrm{O}$ solution of 5-hydroxyuridine by Fox and coworkers. $\left.{ }^{6}\right)$

TABLE I. Chemical Shifts of 5-Oxo,5,6-dihydrouracil Phenylhydrazone in DMSO- $d^{6}$

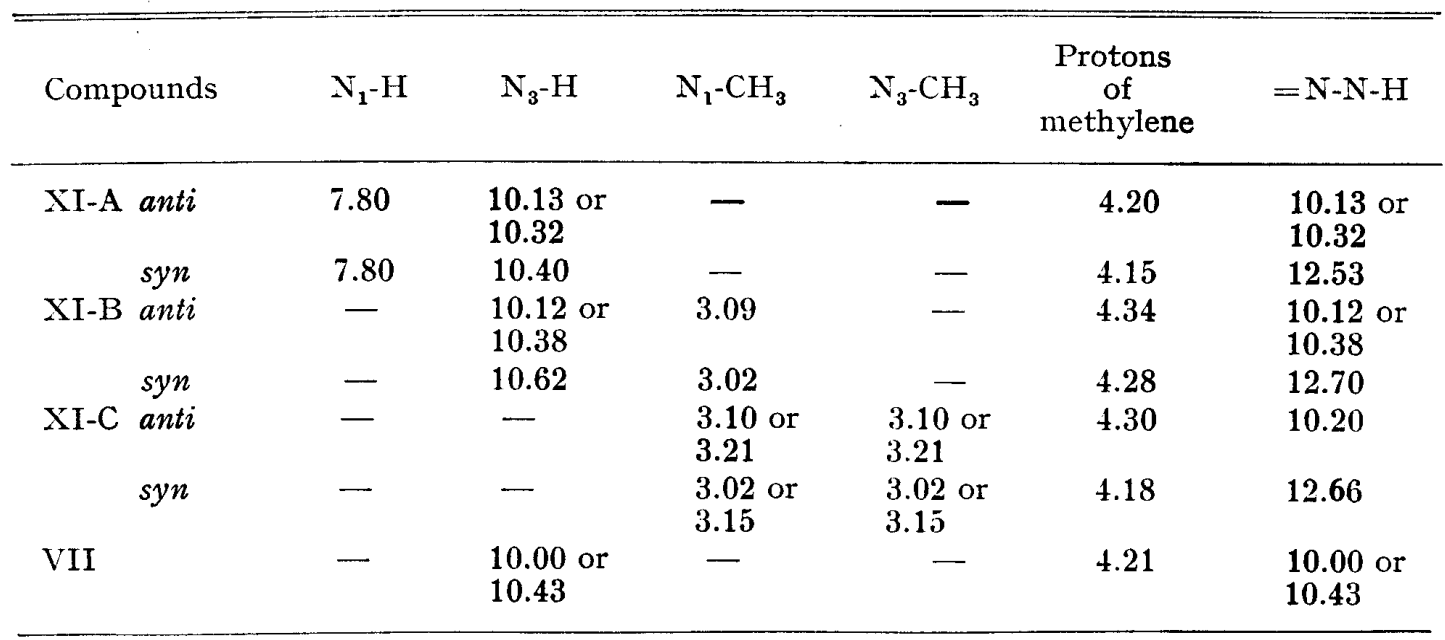

These values were given in $\delta$ value (ppm) with respect to TMS as an internal reference. The chemical shift of protons of benzene residue was to 7.5 from 7.1 .

"Levene's 5,6-diphenylhydrazinouridine" was prepared essentially according to the original report.4) The compound had the same melting point as reported and had elemental composition compatible with III. On reduction of the "Levene's compound" with a number of reducting agents such as, zinc powder in acetic acid or catalytic reduction with catalysts, expected diaminouridine was not obtained. When two molar equivalents of hydrogen were absorbed in the catalytic reduction, the UV absorption spectrum of the reaction mixture showed only end absorption. In the case of zinc powder-acetic acid reduction, acetanilide and sirupy products were obtained. The sirupy substance having only end absorption could not be purified and therefore failed to be characterized.

5) R.A. Abramouitch and I.D. Spenser, J. Chem. Soc., 1957, 3767.

.6) B.A. Otter, E.A. Falco and J.J. Fox, J. Org. Chem., 34, 2636 (1969). 


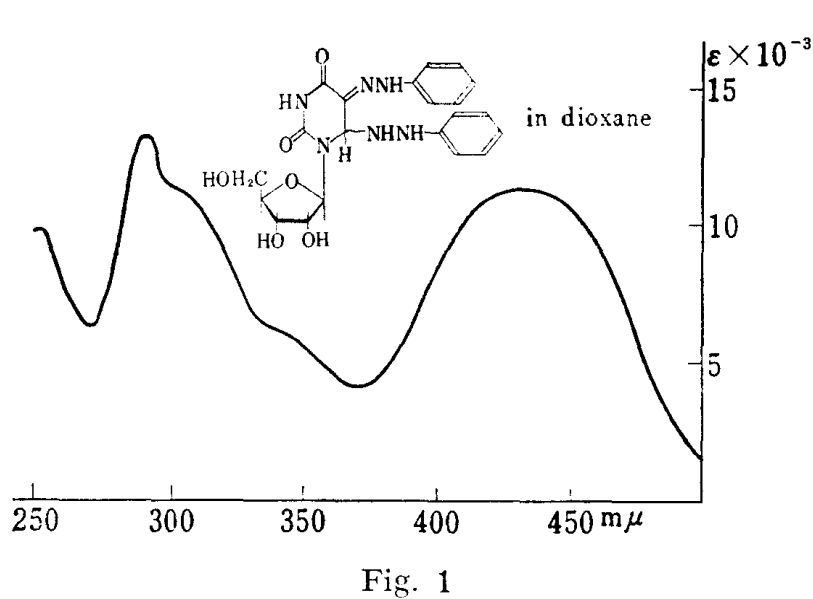

Fig. 1
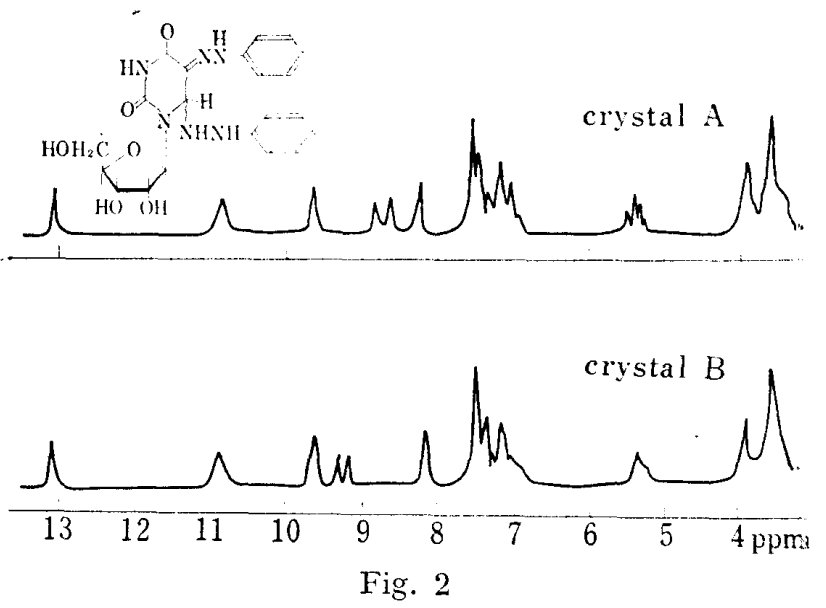

TMS was used as an internal reference.

Upon several recrystallizations from dioxane, so-called "Levene's 5,6-diphenylhydrazinonridine" was separatedinto two different types of crystals (crystal A, mp $226^{\circ}$, crystal B, mp. $229-231^{\circ}$ ), both of which showed similar UV absorption spectra as given in Fig. 1 . However, the specific rotations determined in DMSO of crystal A and B were $-1.2^{\circ}$ and $-30.9^{\circ}$, respectively. If 5,6-dihydrazinouridine structure were assigned to these materials, the existence of two optical isomers can not be reasonable. As shown on Fig. 2, on the NMR spectra in DMSO, signals due to $\mathrm{N}-\mathrm{H}$ resonance appeared at $\delta 13.15,10.91,9.67$ and $8.75 \mathrm{ppm}$ in the case of crystal A, and $\delta 13.15,10.91,9.67$ and $9.30 \mathrm{ppm}$ in the case of crystal B. These signals disappeared on addition of $\mathrm{D}_{2} \mathrm{O}$, whereas NMR spectra of both crystals showed additional signal at $\delta 8.23 \mathrm{ppm}$ in DMSO whose signals did not disappear even after the addition of $\mathrm{D}_{2} \mathrm{O}$. If 5,6-diphenylhydrazinouridine were assigned to this compound, there are five protons bound with nitrogen atom $(\mathrm{N}-\mathrm{H})$ and signals due to these protons should disappear in $\mathrm{D}_{2} \mathrm{O}$. However, in reality, according to deuterium exchange experiments, this compound has only four exchangeable protons. In addition, the assignment of a remaining signal at $\delta 8.23$ was infeasible in term of the Levene's structure (III). These data show that the crystal A and B should be assigned the 5-oxo-6-phenylhydrazino-5,6-dihydrouridine phenylhydrazone (IIa) or 6-oxo5-phenylhydrazino-5,6-dihydrouridine phenylhydrazone (IIb) structure rather than the 5,6diphenylhydrazinouridine structure (III). Carbonyl residue at position 5 of the pyrimidine moiety may react with phenylhydrazine to give phenylhydrazone as is the case with alloxane ${ }^{7 \text { ) }}$ or isodialuric acid, ${ }^{8)}$ whereas carbonyl on positions 2 and $4(6)$ fail to react with phenylhydrazine. Accordingly, crystal A and B were not positional isomers, but configurational isomers. due to different configuration of a proton or a phenylhydrazino grouping at position 6 of IIa. Although compound IIa seemed to be tautomer of structure III, the conversion of IIa into. III was not observed. Compound IIa could be also prepared by following series of reactions: 5 -hydroxyuridine (VI) $\rightarrow$ isodialuric acid riboside $(\mathrm{IV}) \rightarrow 5$-phenylazouridine $(\mathrm{V}) \rightarrow$ IIa. Namely, 5 -hydroxyuridine was treated with aqueous bromine at $30^{\circ}$ to afford isodialuric acid riboside (5-oxo-6-hydroxy-5,6-dihydrouridine IV) according to the description of the reaction of 5hydroxyuracil with bromine in water. ${ }^{8)}$ 5-Phenylazouridine (V) was obtained by the reaction of IV with phenylhydrazine according to the report for synthesis of 5-phenylazouracil.9r 5-Phenylazouridine was heated with phenylhydrazine in acetate buffer at $\mathrm{pH} 4$ to obtain compound IIa. It is presumed that there are two routes on the formation of IIa from uridine: route $\mathrm{A}$ and $\mathrm{B}$ shown in Chart 2. The route $\mathrm{A}$ is most probably acceptable accoring

7) O. Kuhling, Chem. Ber., 23, 4140 (1891).

8) R. Behrend and O. Roosen, Ann., 251, 235 (1889).

9) M.T. Bogert and D. Davidson, Proc. Natl. Acad. Sci., 18, 21 (1932). 


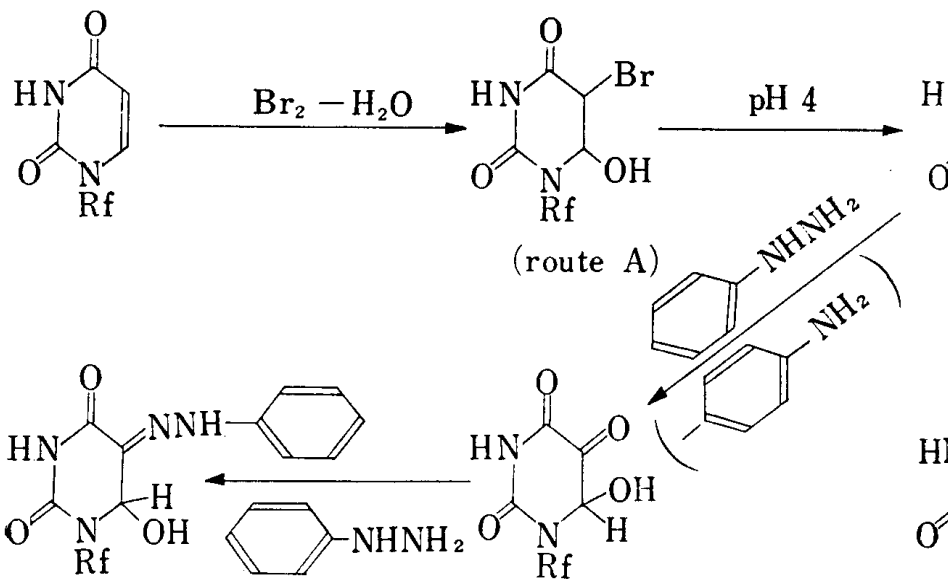<smiles>NNc1ccccc1N</smiles><smiles>O</smiles><smiles>[R17]C1NC(=O)NC(=C)C1O</smiles><smiles>NNc1ccccc1N</smiles><smiles>[R1]C1NC(=O)C(=O)C(=O)NC1=O</smiles>

Chart 2

to the fact that compound IIa was formed from $\mathrm{V}$ through IV, though the route $\mathrm{B}$ can not be absolutly discarded because of no investigation to check the mode. One of the features of reactions consists in oxidation of hydroxyl group on position 5 to 5 -oxo group. For the reaction of the oxidation, one mole of phenylhydrazine should be comsumed to form aniline. In fact aniline could be detected from the reaction mixture.

In short, the structures of Levene's 5-phenylhydrazinouracil derivatives and 5,6-diphenylhydrazinouridine should be revised to 5-oxo-5,6-dihydrouracil phenylhydrazone derivatives and 5-oxo-6-phenylhydrazino-5,6-dihydrouridine phenylhydrazone, respectively.

Although it has been reported by Levene ${ }^{4)}$ that brominated uracil was reacted with phenylhydrazine to give 5-phenylhydrazinouracil (VIII), its structure should be also revised to 5-oxo-5,6-dihydrouracil phenylhydrazone (XIA), on the basis of the same line of reasonings mentioned above.

The synthesis of uric acid 3-riboside from uridine will be reported later.

\section{Experimental}

5-0x0-6-phenylhydrazino-5,6-dihydrouridine Phenylhydrazone (IIa)__Method A: Uridine (1.0 g) was treated with bromine-water until the solution was persistently yellow and then excess bromine was removed by bubbling air. The solution was added to a mixture of $3.0 \mathrm{~g}$ of sodium acetate, $5.0 \mathrm{~g}$ of phenylhydrazine and $10 \mathrm{ml}$ of acetic acid and heated on boiling water bath for two hours. After cooling, precipitates were filtrated and washed with water, ethanol and ether, and finally dried. The precipitates were crystallized from methanol. The crystal was again recrystallized from tert-butanol to give the yellow crystal, $\mathrm{mp} 212^{\circ}$; yield $1.5 \mathrm{~g}(80 \%)$. The yellow crystal $(1.0 \mathrm{~g})$ was dissolved in $20 \mathrm{ml}$ of hot dioxane and the solution was kept at room temperature to yield $600 \mathrm{mg}$ of crystal $\mathrm{A}, \mathrm{mp} 226^{\circ}$. The mother liquid was kept standing further for four days at room temperature to obtain crystal B. The crystal B was recrystallized from a small volume of dioxane to yield $150 \mathrm{mg}$, mp 229-231 . Anal. Calcd. for $\mathrm{C}_{21} \mathrm{H}_{24} \mathrm{O}_{6} \mathrm{~N}_{6}: \mathrm{C}, 55.25 ; \mathrm{H}, 5.30 ; \mathrm{N}$, 18.41. Found: crystal A; C, 55.00; H, 5.44; N, 18.64. Crystal B; C, 54.95; H, 5.30; N, 18.41. $[\alpha]_{\mathrm{D}}^{20} ;$ crystal $\mathrm{A},-1.2^{\circ}$; crystal $\mathrm{B},-30.9^{\circ}(c=2.0, \mathrm{DMSO})$. The UV and NMR spectra were shown in Fig. 1 and 2 , respectively.

Method B: Phenylazouridine $(348 \mathrm{mg})$ was added to a mixture of $0.5 \mathrm{~g}$ of sodium acetate, $1.0 \mathrm{ml}$ of acetic acid and $160 \mathrm{mg}$ of phenylhydrazine in $10 \mathrm{ml}$ of water. The solution was heated on boiling water 
bath for $30 \mathrm{~min}$. After cooling, precipitates were separated by filtration and washed with water, ethanol, and then ether. The precipitates were crystallized from methanol to yield $385 \mathrm{mg}$ of yellow crystal, mp $213^{\circ}$. The mixed melting point with the above crystal crystallized from tert-butanol, gave $213^{\circ}$. V, UV $\lambda_{\max }^{\text {dloxane }} \mathrm{m} \mu(\varepsilon): 430(11500), 350$ (infl. 5550), 310 (infl. 11000), 290 (13300), 253 (10000). This spectrum was in agreement with that of IIa from method $A$.

The Detection of Aniline- The mother liquid of the reaction mixture ${ }^{10}$ ) of the method A was adjusted to $\mathrm{pH} 2$ with $1 \mathrm{~N} \mathrm{HCl}$ and concentrated to dryness. To the residue was added $10 \mathrm{ml}$ of $50 \% \mathrm{NaOH}$ and the alkaline solution was extracted with ether. The thin-layer chromatography of the ether layer on silicagel, ${ }^{11)}$ gave two spots of $R f 0.81$ (aniline) and 0.61 (phenylhydrazine) detectable with UV-lamp and the nitrous acid- $p$-dimethylaminobenzaldehyde test. The paper chromatography ${ }^{12)}$ of the ether layer gave $R f 0.06$ (phenylhydrazine) and 0.14 (aniline).

5-Phenylazouridine-5-Hydroxyuridine $(2.5 \mathrm{~g})$ was added to $10 \mathrm{ml}$ of water. Bromine $(0.7 \mathrm{ml})$ was dropwise added to the solution with stirring. After the reaction mixture was allowed to warm up to $30^{\circ}$ and was kept for $30 \mathrm{~min}, 5.0 \mathrm{~g}$ of silver carbonate and $40 \mathrm{ml}$ of water were added and the mixture was stirred for one hour at room temperature. The reaction mixture was filtrated. The filtrates were concentrated under reduced pressure to give white amorphous solid $(2.5 \mathrm{~g})$. The paper chromatography of the solid gave a single spot; Rf 0.57 with propanol-water $(3: 2), 0.19$ with iso-propanol-water-conc. ammonia $(7: 2: 1)$ and 0.08 with butanol-acetic acid-water $(5: 3: 2)$. UV spectra of the solid showed end absorption in both water and alkaline solution. The solid was used for the following reaction.

The white solid $(1.33 \mathrm{~g})$ was added to a mixture of $5.0 \mathrm{ml}$ of acetic acid, $1.5 \mathrm{~g}$ of sodium acetate and $1.8 \mathrm{~g}$ of phenylhydrazine in $20 \mathrm{ml}$ of water. The reaction mixture was kept at room temperature for 2 days to obtain precipitates which were collected by filtration. The precipitates were crystallized from methyl cellosolve to yield $1.2 \mathrm{~g}$ of 5 -phenylazouridine $\left(\mathrm{mp} 212^{\circ}, 70 \%\right)$. Anal. Calcd. for $\mathrm{C}_{15} \mathrm{H}_{16} \mathrm{O}_{6} \mathrm{~N}_{4}$ : C, 51.72; $\mathrm{H}, 4.63 ; \mathrm{N}, 16.09$. Found: $\mathrm{C}, 51.89 ; \mathrm{H}, 4.76 ; \mathrm{N}, 15.68$. UV $\lambda_{\max }^{\mathrm{EtoH}} \mathrm{m} \mu(\varepsilon): 366(15000), 280$ (infl. 1400$)$, $240(7100)$.

anti-5-0x0-5,6-dihydrouracil Phenylhydrazone (XIA-anti)—-5-Hydroxyuracil (500 $\mathrm{mg}$ ) was added to a solution containing $1.5 \mathrm{~g}$ of sodium acetate, $5.0 \mathrm{ml}$ of acetic acid, $2.5 \mathrm{~g}$ of phenylhydrazine and $50 \mathrm{ml}$ of water. After the solution was heated in boiling water-bath for 2 hours, the reaction mixture was cooled to obtain precipitates. The precipitates were washed with water, ethanol and finally ether, and then dried to yield $580 \mathrm{mg}$ of XIA-anti (mp 252, $60 \%$ ). Anal. Calcd. for $\mathrm{C}_{10} \mathrm{H}_{10} \mathrm{O}_{2} \mathrm{~N}_{4}: \mathrm{C}, 55.05 ; \mathrm{H}, 4.59 ; \mathrm{N}, 25.69$. Found: C, 55.26; H, 4.58; N, 25.40. UV $\lambda_{\max }^{\mathrm{EtOH}} \mathrm{m} \mu(\varepsilon): 340$ (23000), 295 (4800), 285 (infl. 4000), 234 (13800).

syn-5-0xo-5,6-dihydrouracil Phenylhydrazone (XIA-8yn)—Compound XIA-anti (500 mg) was added to $.5 \mathrm{ml}$ of methyl cellosolve and the resulting mixture was heated in reflux for 4 hours. The UV spectrum of the reaction mixture showed $\lambda_{\max }$ at $360 \mathrm{~m} \mu$. The reaction mixture was cooled rapidly and then crystal deposited was filtrated, washed with ethanol and ether, and dried to yield $300 \mathrm{mg}$ of the $s y n$-form $\left(\mathrm{mp} 243^{\circ}\right.$, $60 \%$ ). Anal. Calcd. for $\mathrm{C}_{10} \mathrm{H}_{10} \mathrm{O}_{2} \mathrm{~N}_{4}: \mathrm{C}, 55.05 ; \mathrm{H}, 4.59 ; \mathrm{N}, 25.69$. Found: $\mathrm{C}, 55.06 ; \mathrm{H}, 4.71 ; \mathrm{N}, 25.68$. $\mathrm{UV} \lambda_{\max }^{\mathrm{EtOH}} \mathrm{m} \mu(\varepsilon): 360(15300), 290$ (infl. 2300), 240 (10000).

The Intercoversion of XIA-syn into XIA-anti-A solution of XIA-syn in dimethyl sulfoxide- $\mathrm{d}^{6}$ was allowed to stand at room temperature. The solution showed $\lambda_{\max }$ at $355 \mathrm{~m} \mu$ after 24 hours, $350 \mathrm{~m} \mu$ after 2 days and finally $342 \mathrm{~m} \mu$ after 4 days in UV spectra. In the NMR spectra the signals of the solution after 4 days, appeared in $\delta \mathrm{ppm} 4.15-4.20(2 \mathrm{H}), 7.2-7.5(5 \mathrm{H}), 7.80(1 \mathrm{H}), 10.13(0.75 \mathrm{H}), 10.32(0.75 \mathrm{H}), 10.40$ $(0.25 \mathrm{H})$ and $12.53(0.25 \mathrm{H})$.

anti-1-methyl-5-oxo-5,6-dihydrouracil Phenylhydrazone (XIB-anti)-1-Methyl-5-hydroxyuracil (500 $\mathrm{mg}$ ) was added to the solution containing $5.0 \mathrm{ml}$ of acetic acid. $1.5 \mathrm{~g}$ of sodium acetate and $2.5 \mathrm{~g}$ of phenylhydrazine in $20 \mathrm{ml}$ of water. After the solution was heated in boiling water-bath for 2 hours and cooled, the crystal was filtrated and washed with water, ethanol and ether, and then dried to yield $650 \mathrm{mg}$ of XIBanti (mp 231-231.5, $71 \%$ ). Anal. Calcd. for $\mathrm{C}_{11} \mathrm{H}_{12} \mathrm{O}_{2} \mathrm{~N}_{4}: \mathrm{C}, 56.96 ; \mathrm{H}, 5.71 ; \mathrm{N}, 24.14$. Found: $\mathrm{C}, 56.57$; $\mathrm{H}, 5.22 ; \mathrm{N}, 23.89 . \mathrm{UV} \lambda_{\max }^{\mathrm{EtOH}} \mathrm{m} \mu(\varepsilon): 342(23500), 295$ (5000), 285 (infl. 4200), 234 (14100).

The Intercoversion of XIB-anti into syn-1-Methyl-5-oxo-5,6-dihydrouracil Phenylhydrazone (XIB-syn)

A suspension of $600 \mathrm{mg}$ of XIB-anti in $10 \mathrm{ml}$ of methyl cellosolve, was refluxed for 5 hours. After the solution was filtrated while hot, crystals were obtained by cooling. The crystals were washed with a small volume of methyl cellosolve, ethanol and ether, and then dried. They were a mixture of yellow prism-shaped crystal (crystal 1) and tiny needle-shaped crystals (crystal 2). Crystal 1 and crystal 2 were separated carefully from the mixture with a pinsette to yield crystal $1(480 \mathrm{mg}$ of the syn-form, mp 205-207 $)$ and crystal $2\left(90 \mathrm{mg}\right.$ of the anti-form, $\left.\mathrm{mp} 231^{\circ}\right)$. Anal. Calcd. for $\mathrm{C}_{11} \mathrm{H}_{12} \mathrm{O}_{2} \mathrm{~N}_{4}$ (XIB-syn; crystal 1): C, 56.96; $\mathrm{H}, 5.17 ; \mathrm{N}, 24.14$. Found: C, 56.85; H, 5.22; N, 24.35. UV $\lambda_{\max }^{\mathrm{EtOH}} \operatorname{m} \mu(\varepsilon): 366(15500), 290$ (infl. 2300),

10) Aniline-free phenylhydrazine was used on this reaction.

11) Chloroform-ethanol $(35: 5)$ was used as the solvent system.

12) The ascending technique was used in all paper chromatographies. On this case, the solvent system was the upper phase of methanol, amylalchol, benzene, $2 \mathrm{~N} \mathrm{HCl}(35: 17.5: 35: 12.5)$. 
239 (10200). The crystal 2 was identified with XIB-anti by the mixed examination and its NMR and UV spectra.

anti-1,3-Dimethyl-5-oxo-5,6-dihydrouracil Phenylhydrazone (XIC-anti) — 1,3-Dimethyl-5-hydroxyuracil $(500 \mathrm{mg})$ was added to a solution containing $5.0 \mathrm{ml}$ of acetic acid, $1.5 \mathrm{~g}$ of sodium acetate and $2.5 \mathrm{~g}$ of phenylhydrazine in $15 \mathrm{ml}$ of water. After the solution was heated in boiling water-bath for 2 hours, the reaction mixture was cooled and precipitates were collected by filtration. The precipitates were washed with water, ethanol and ether, and crystallized from ethanol to yield $600 \mathrm{mg}$ of XIC-anti (mp 206-208 ${ }^{\circ}, 78 \%$ ). Anal. Calcd. for $\mathrm{C}_{12} \mathrm{H}_{14} \mathrm{O}_{2} \mathrm{~N}_{4}$ : C, 58.52; H, 5.73; N, 22.75. Found: C, 58.48; H, 5.74; N, 22.66. UV $\lambda_{\max }^{\text {Etor }}$ $\mathrm{m} \mu(\varepsilon): 342(23600), 295(4900), 285$ (infl. 4200), 234 (14000).

syn-1,3-Dimethyl-5-oxo-5,6-dihydrouracil Phenylhydrazone (XIC-syn)__A suspension of $200 \mathrm{mg}$ of XIC-anti in $2.0 \mathrm{ml}$ of methyl cellosolve was refluxed for 10 hours. The solution was allowed to stand overnight to give $80 \mathrm{mg}$ of XIC-syn (mp 116-121 $)$. Anal. Calcd. for $\mathrm{C}_{12} \mathrm{H}_{14} \mathrm{O}_{2} \mathrm{~N}_{4}: \mathrm{C}, 58.52 ; \mathrm{H}, 5.73 ; \mathrm{N}$, 22.75. Found: C, 58.72; H, 5.42; N, 22.53. UV $\lambda_{\max }^{\text {Btort }} \mathrm{m} \mu(\varepsilon): 367$ (15500), 290 (infl. 2200), $239(10100)$.

anti-5-0xo-5,6-dihydrouridine Phenylhydrazone (VII) - 5-Hydroxyuridine $(1.0 \mathrm{~g})$ was added to a solution containing $10 \mathrm{ml}$ of acetic acid, $3.0 \mathrm{~g}$ of sodium acetate and $5.0 \mathrm{~g}$ of phenylhydrazine in $100 \mathrm{ml}$ of water. After the solution was heated in boiling water-bath for 2 hours and allowed to cool. The precipitates formed from the reaction mixture, were filtrated and washed with water, ethanol and ether. The precipitates were crystallized from ethanol to yield $1.0 \mathrm{~g}$ of VII (mp 202, $70 \%$ ). Anal. Calcd. for $\mathrm{C}_{15} \mathrm{H}_{18} \mathrm{O}_{6} \mathrm{~N}_{4}$ : $\mathrm{C}, 51.42 ; \mathrm{H}, 5.18 ; \mathrm{N}, 15.99$. Found: $\mathrm{C}, 51.14 ; \mathrm{H}, 5.43 ; \mathrm{N}, 15.67$. UV $\lambda_{\max }^{\mathrm{EtoH}} \mathrm{m} \mu(\varepsilon): 342(23300), 294.5$ (5000), 285 (4300), $233(14000)$.

The Reduction of 5-Phenylazouridine (Synthesis of VII from V) -5 -Phenylazouridine (348 $\mathrm{mg})$ in $20 \mathrm{ml}$ of methyl cellosolve was hydrogenated with Raney nickel W-2 as catalyst. When one equivalent of hydrogen was comsumed, the mixture was warmed and the catalyst was filtrated off from the mixture. The solution was concentrated to dryness under reduced pressure. The residue was crystallized from ethanol

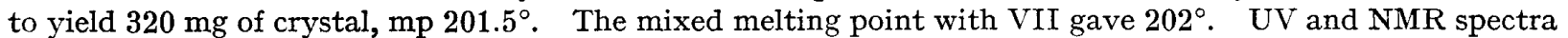
of the crystal were in agreement with those of VII.

The Deuteration of 5-Hydroxyuridine (6-Deutero-5-hydroxyuridine)—5-Hydroxyuridine ( $30 \mathrm{mg}$ ) was added to a solution containing $0.05 \mathrm{ml}$ of $30 \% \mathrm{NaOD}$ (in $\mathrm{D}_{2} \mathrm{O}$ ), $0.1 \mathrm{ml}$ of acetic acid-d in $0.35 \mathrm{ml}$ of $\mathrm{D}_{2} \mathrm{O}$. In the NMR spectrum of the mixture, the signal due to a proton on position 6 of 5 -hydroxyuridine appeared at $7.45 \mathrm{ppm}$. After the solution was heated in boiling water-bath for 2 hours, the signal disappeared. The solution was allowed to stand in ice box overnight to give crystal. The crystal was washed with cold water to yield $20 \mathrm{mg}$ of 6-deutero-5-hydroxyuridine, $\mathrm{mp} 235^{\circ}$. UV $\lambda_{\max } \mathrm{m} \mu: 283\left(\mathrm{H}_{2} \mathrm{O}\right), 305(0.1 \mathrm{~N} \mathrm{NaOH})$.

Acknowledgement The authors are grateful to Dr. T. Ueda of this Faculty for his valuable discussions. Thanks are also due to Mrs. T. Tohma and Miss A. Maeda of the analytical laboratory of this Faculty for elemental analyses, and to Miss Y. Kishio of this Faculty for NMR spectral determination. 